Cadernos de Arquitetura e Urbanismo, v.17, n.20, 2010 
tint

W

W. 1.5.

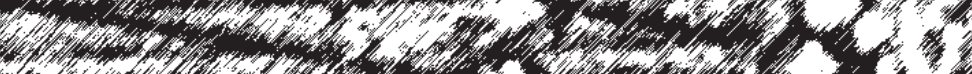
4.

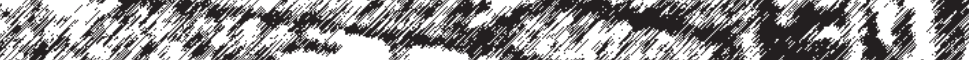

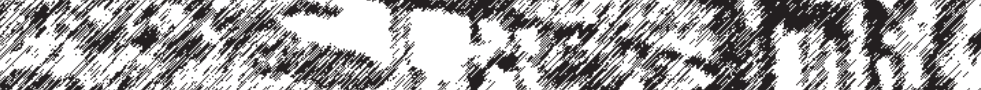

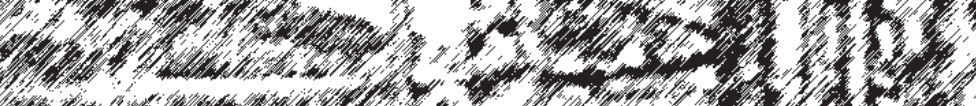
等,

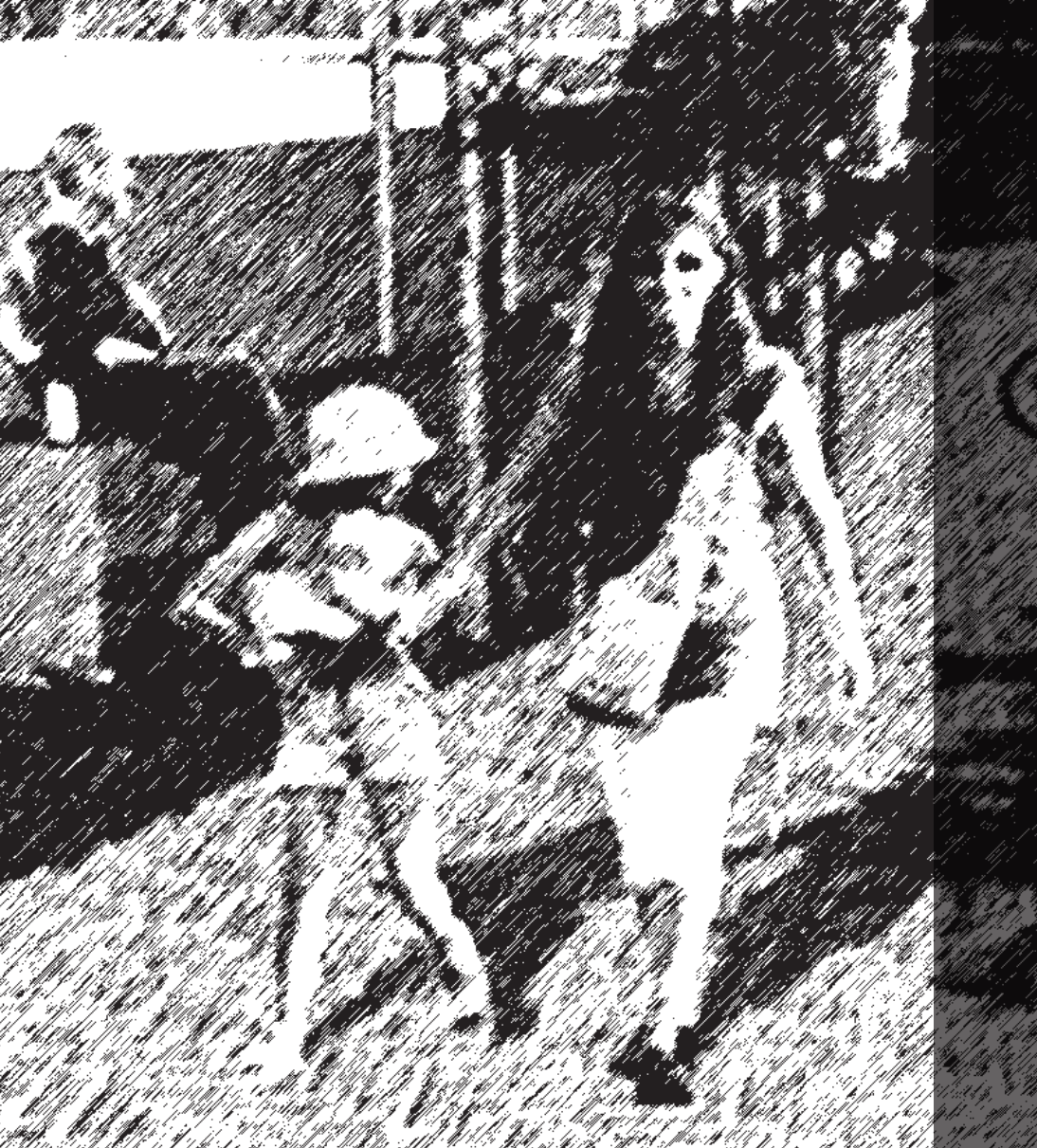

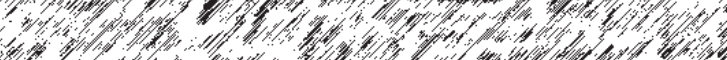

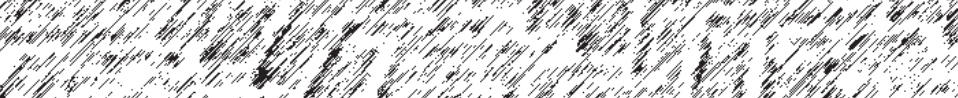

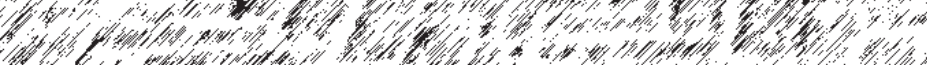

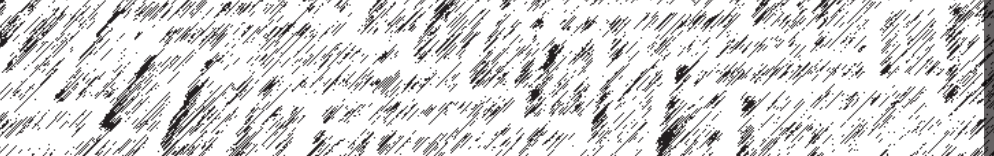

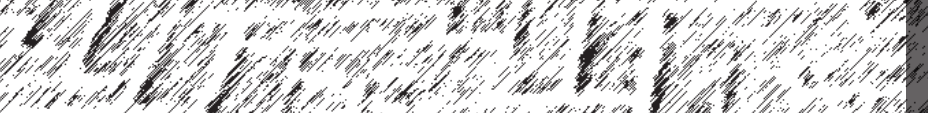

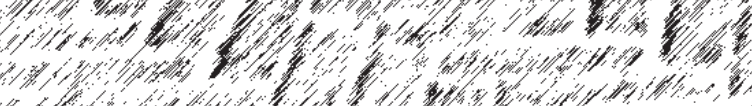




\title{
SUSTENTABILIDADE E EDUCAÇÃO AMBIENTAL NO CURSO DE ARQUITETURA E URBANISMO
}

SUSTAINABILITY AND ENVIRONMENTAL EDUCATION IN ARCHITECTURE AND URBANISM PROGRAMS

Márcia Bissoli

\section{Resumo}

Este artigo objetiva apresentar uma proposta metodológica com embasamento sustentável, de uma disciplina do curso de Arquitetura e Urbanismo da Universidade Federal do Espírito Santo (UFES). Debate a inserção dos conceitos relacionados a sustentabilidade e educação ambiental, diante dos novos desafios correlatos a estes. Os resultados mostram que a inclusão desses conceitos em disciplinas acadêmicas tem fundamental relevância para a formação de uma nova geração de profissionais. Para os arquitetos, contribui para uma formação direcionada a sociedades sustentáveis.

Palavras-chave: Sustentabilidade na arquitetura; Ensino e sustentabilidade; Educação ambiental; Arquitetura sustentável.

\begin{abstract}
This article presents a methodology, with a sustainable foundation, for the program of Architecture and Urbanism of the Universidade Federal do Espírito Santo - UFES (Federal University of Espírito Santo State, Brazil). It discusses the inclusion of concepts related to sustainability and environmental education, in face of new challenges related to them. Results show that the inclusion of those concepts in academic courses is absolutely relevant to the formation of a new generation of professionals. For architects, it contributes to an education directed towards sustainable societies.
\end{abstract}

Key words: Sustainability in architecture; Teaching and sustainability; Environmental education; Sustainable architecture. 
O ser humano está cada vez mais envolvido com as novas tecnologias e desafios impostos pelos cenários urbanos, o que vem provocando a perda da relação natural com a terra e com as culturas. Projetar deveria significar cultivar biodiversidade, restaurar terras e águas, conservar a cobertura vegetal e, ao mesmo tempo, incorporar um conjunto de estratégias de sobrevivência como: moradia, trabalho, alimentação, saneamento, manufatura, lazer, vida social e comércio, em proporções balanceadas (ANDRADE; ROMERO, 2004). Os conceitos baseados no desenvolvimento sustentável se apresentam como uma ferramenta essencial na formação do arquiteto e urbanista em particular, dada a possibilidade de sua produção atingir grande parte dos cidadãos, seja no morar, no trabalhar, no conviver ou simplesmente na percepção do espaço construído, o qual integra a paisagem urbana.

As instituições de ensino são as maiores responsáveis pela educação do indivíduo e, consequentemente, da sociedade. Adotar um modelo de educação apoiado nos aspectos ambientais e no desenvolvimento sustentável se mostra uma decisão pertinente dentro dos atuais modelos de desenvolvimento da sociedade. Nesse sentido, a Lei n 9.795 de 27 de abril de 1999, que institui a Política Nacional de Educação Ambiental, entende por educação ambiental "os processos por meio dos quais o indivíduo e a coletividade constroem valores sociais, conhecimentos, habilidades, atitudes e competências voltadas para a conservação do meio ambiente" (BRASIL, 1999).

Para que tais valores sejam acatados, é necessário provocar a quebra de paradigmas e vislumbrar novos caminhos, considerando os ensinamentos direcionados ao uso racional dos recursos naturais e à conservação de um índice de produtividade dos ecossistemas naturais ou aqueles administrados pelo homem (BRÜGGER, 1999). Essa mesma autora defende que a educação seja para o meio ambiente e isso envolve uma intensa mudança de valores.

Mudanças também devem ocorrer nos currículos, para que as disciplinas possam se tornar menos estanques e mais transdisciplinares, ou seja, que as abordagens possam atuar entre, além e através das disciplinas. De acordo com Brügger (1999, p. 37), a adoção desse modelo "deveria envolver não apenas uma reavaliação da estrutura departamentalizada das universidades e outras instituições de ensino, mas principalmente uma análise crítica dos conteúdos ministrados e conceitos que estruturam o pensamento hegemônico". Apresenta-se assim a viabilidade de mesclar o assunto a outros temas de disciplinas já consolidadas conceitualmente.

\section{Materiais e métodos}

Considerando que o recorte do objeto é o curso de Arquitetura e Urbanismo da Universidade Federal do Espírito Santo, a metodologia elaborada foi aperfeiçoada a partir da experiência obtida no decorrer da disciplina Projetos Especiais, a qual possui ementa livre e é oferecida aos graduandos provenientes dos três últimos semestres. A metodologia foi testada durante quatro semestres letivos, percorrendo os meses de março/2007 a dezembro/2008, e envolveu aproximadamente 100 discentes. 
2. Para conhecer metodologia semelhante, sugere-se consultar Duarte; Mulfarth e Gonçalves, 2007.
Figura 1 - Esquema das atividades que compõem a metodologia.
A proposta aqui visa apresentar uma experiência de metodologia $^{2}$ que engloba a ementa da disciplina Arquitetura Sustentável e Educação Ambiental, com o intuito de verificar a possibilidade de replicar tal proposta em outras disciplinas e cursos acadêmicos, além de testar e ajustar o que for necessário.

Como atividade acadêmica principal, propõe-se o desenvolvimento de um ensaio projetual alicerçado em diretrizes sustentáveis. Em consonância, são discutidos conceitos sustentáveis, valores ambientais, novas tecnologias construtivas para formação de uma percepção ambiental e holística dos graduandos. São aqui apresentadas algumas dessas estratégias adotadas para o ensino, através da Figura 1. A disciplina encontra-se dividida em três partes, aqui denominadas blocos, cada qual subdividido em diferentes etapas.

Em cada atividade da disciplina é proposto um trabalho de investigação, com o intuito de observar reflexões e ações possíveis de serem desencadeadas pelo grupo, e um consequente envolvimento de todos os alunos. Não se trata de identificar níveis ou estágios de evolução dos envolvidos, pois cada indivíduo possui seu particular processo de aprendizagem.

Para o desenvolvimento das atividades, os alunos são divididos em grupos de, no máximo, quatro membros. Em relação a grupos de trabalho montados para estudar temas relacionados à educação ambiental, Tristão (2004, p. 43) comenta a importância de tal iniciativa, visto que essa decisão promove "a participação e a reflexão coletiva e não, simplesmente, é uma mera função de distribuição de tarefas, fragmentando o conhecimento e as pessoas".

Procura-se, dessa maneira, compreender as interações entre os participantes, a atuação coletiva, a convivência, a consideração pelas diferenças existentes e a cooperação entre todos, bus-

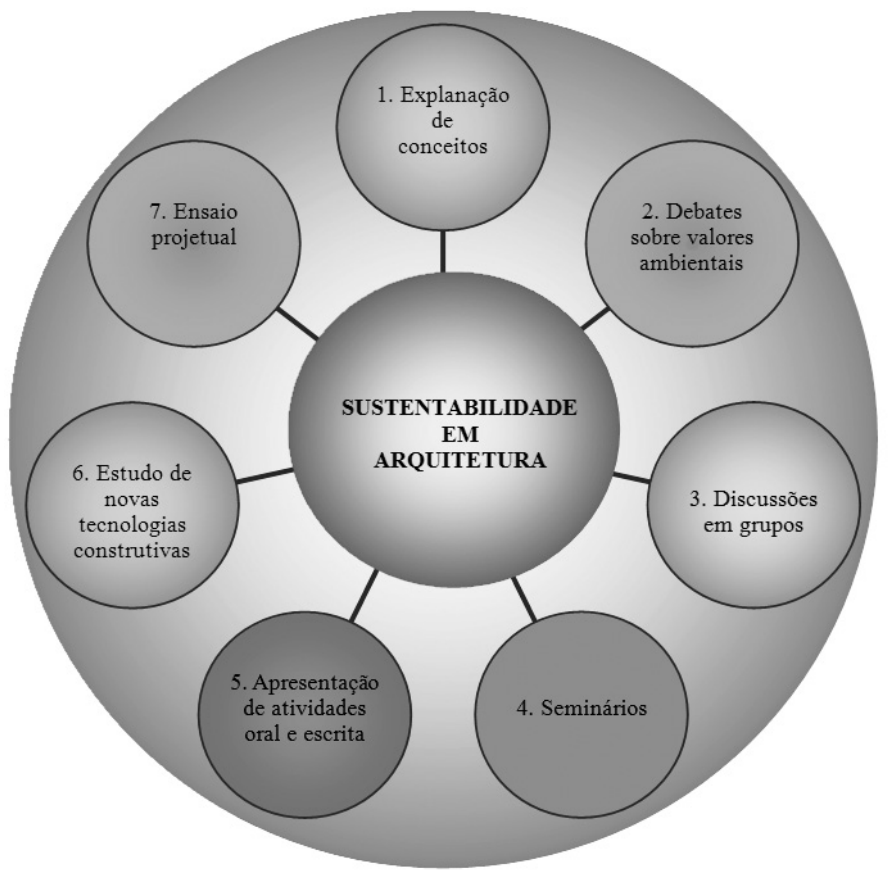


cando-se, assim, desenvolver práticas de educação ambiental. A ação em grupo coopera também para uma reflexão que conduz à descoberta de novas ideias e percepções, através da diversidade de conhecimentos dos componentes, sejam contradições, incoerências ou simplesmente, debates sobre determinados assuntos.

\section{Estratégias de ensino para a educação ambiental em Arquitetura}

De acordo com o disposto na Lei $n^{\circ}$ 9.795, como parte do processo educacional mais amplo, todos têm direito à educação ambiental, sendo papel das instituições promoverem tal educação de maneira integrada aos habituais programas educacionais estabelecidos em cada curso. Diante disso, na metodologia apresentada propõe-se o desenvolvimento simultâneo do conhecimento, de habilidades e de atitudes fundamentais à qualidade projetual sustentável e à conscientização da preservação dos bens naturais através da educação ambiental.

Sugere-se, ainda, que estejam em consonância com a melhoria da qualidade de vida e do espaço a ser habitado, seja qual for o tipo de ocupação - residencial, comercial, lazer, estudo etc. A sala de aula, por sua vez, funciona como laboratório, onde são discutidas propostas, desenvolvidos os estudos e apresentadas soluções conceituais e de projeto.

A relação do ser humano com a cidade, os recursos naturais e físicos também são explorados, em conjunto com a relação homem versus ambiente. Para que a aprendizagem seja mais efetiva e prática, propõem-se atividades adaptadas às situações do cotidiano, do ambiente local e da própria cidade. Em relação aos graduandos, a proposta visa estabelecer relações de vivência nos aspectos de funcionalidade, de convivência, de qualidade de vida, de melhorias comportamentais, ambientais, de conforto etc. Assim, percebendo o espaço em que estão inseridos, podem mais facilmente propor novas estratégias de projeto.

O desenvolvimento dos conceitos pertinentes à temática da educação ambiental, arquitetura, urbanismo e paisagismo com base sustentável, percorre várias etapas, dentro de três blocos distintos. No bloco 1 (Discussão) é proposta a interação graduandos versus graduandos e graduandos versus docente, com o intuito de detectar as principais características e os interesses dos envolvidos, além de favorecer os debates, através de um melhor entrosamento. A partir daí são explorados os conceitos por meio de aulas expositivas, filmes e através do conhecimento de iniciativas similares, o que abrange a participação e o envolvimento de todos.

No bloco 2 (Desdobramento) é necessário percorrer quatro etapas distintas. Inicialmente os graduandos são estimulados a discutir conceitos e técnicas sustentáveis, desenvolver os trabaIhos, para posterior apresentação oral e escrita, culminando com o debate. As temáticas exploradas nesse bloco são apresentadas no Quadro 1.

O bloco 3 (Atuação) é considerado a atividade prática. Para tanto, adota-se como objeto de estudo (intervenção ou nova proposta) um local próximo e de conhecimento de todos, para que 


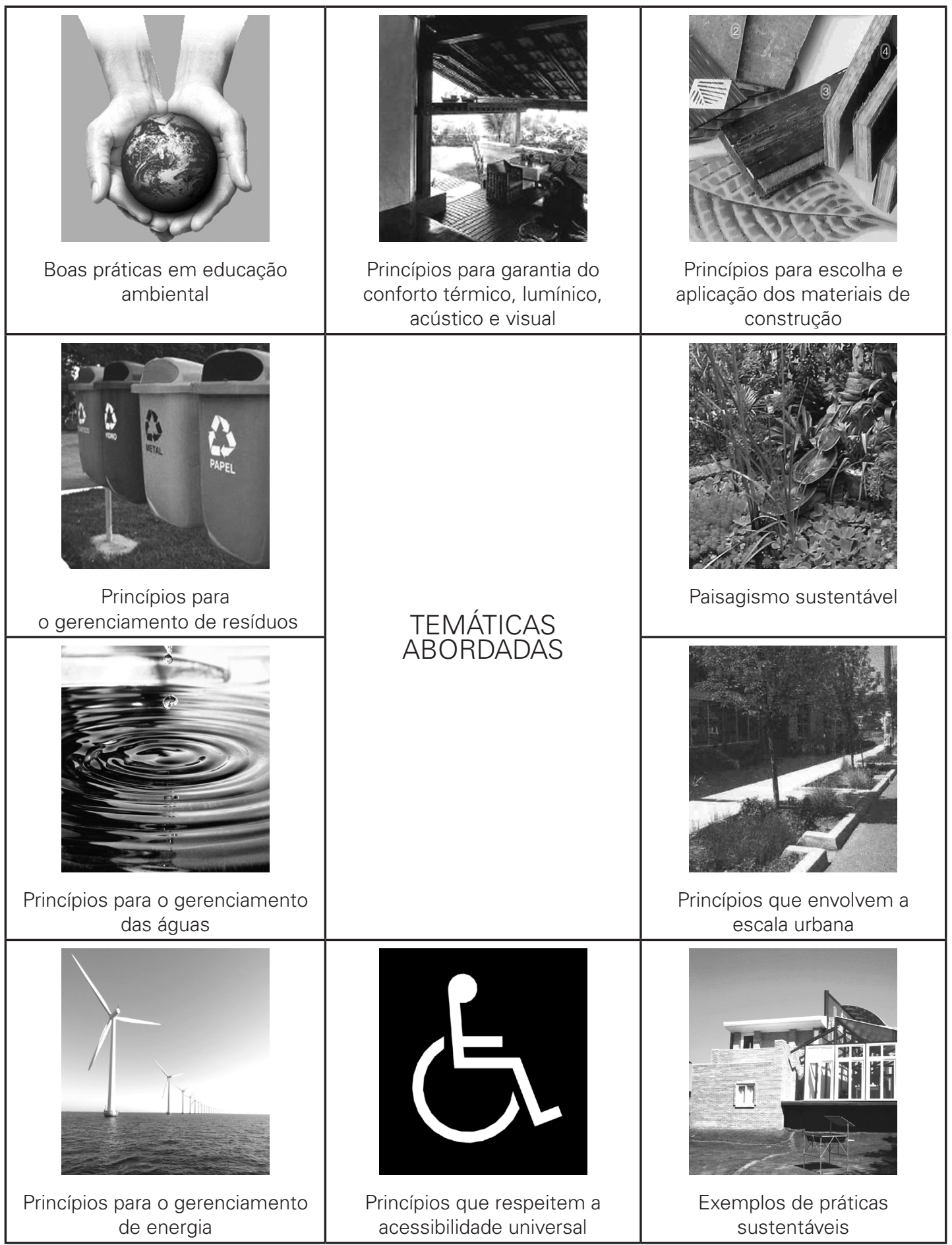

\section{Quadro $1 \bullet$}

Temáticas abordadas na disciplina. Fonte das figuras: Boas práticas: http://farm1.static.flickr.com/122/299637078_9fd860aa6f.jpg. Conforto: http://www.labcon.ufsc.br/anexosg/232.pdf. Materiais: http://www.lets-evo.net/skateboard/wp-content/amostra_comp.jpg. Resíduos: www.reacaoambiental.com.br/?p=311. Paisagismo sustentável: www.pousadajardimdoeden.com.br. Água: http://www. geotrack.com.br/agua.jpg. Escala urbana: PENTEADO, H. Infraestrutura Verde. 2007. Energia: http://europa.eu/scadplus/images/ dossiers_cles/danishwindturbins.jpg. Acessibilidade: http://www.arq.ufsc.br/arq5661/trabalhos_2003-2/acessibilidade_a_deficientes/ imagens/simbolo.jpg. Exemplos de práticas sustentáveis: http://www.eletrosul.gov.br/casaeficiente/br/home/conteudo.php?cd=46 


\begin{tabular}{|c|c|c|c|c|}
\hline Bloco & Etapa & $\begin{array}{l}\text { Parâmetros } \\
\text { referenciais }\end{array}$ & Estratégia adotada & Percepções conclusivas \\
\hline 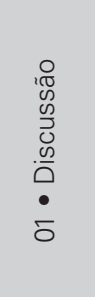 & 01 & $\begin{array}{l}\text { Discussão em } \\
\text { classe (grande } \\
\text { grupo) }\end{array}$ & $\begin{array}{l}\text { Conteúdo teórico exposto para } \\
\text { apresentação dos principais } \\
\text { conceitos, através de aulas } \\
\text { expositivas, filmes e proposta de } \\
\text { discussão por meio de debates: } \\
\text { graduandos expõem suas opiniões } \\
\text { oralmente. }\end{array}$ & $\begin{array}{l}\text { - Melhor entendimento das } \\
\text { questões por parte dos graduandos; } \\
\text { e } \\
\text { - Desenvolvimento da autoconfiança, } \\
\text { da expressão oral e da participação. }\end{array}$ \\
\hline \multirow{4}{*}{ 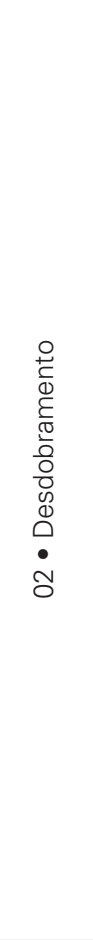 } & 02 & $\begin{array}{l}\text { Discussão em } \\
\text { grupo }\end{array}$ & $\begin{array}{l}\text { Os assuntos são discutidos em } \\
\text { grupos: cada grupo é responsável } \\
\text { pelo estudo de um determinado } \\
\text { tema proposto (quadro 1). }\end{array}$ & $\begin{array}{l}\text { - Desenvolvimento de relações } \\
\text { positivas entre os próprios } \\
\text { graduandos e entre os graduandos e } \\
\text { professor. }\end{array}$ \\
\hline & 03 & $\begin{array}{l}\text { Mutirão de } \\
\text { idéias }\end{array}$ & $\begin{array}{l}\text { Os alunos são incentivados a } \\
\text { pesquisar em diversas fontes, } \\
\text { avaliando propostas dentro da } \\
\text { temática do grupo, estimulando } \\
\text { idéias e coletando o máximo de } \\
\text { informações relevantes. }\end{array}$ & $\begin{array}{l}\text { - Estímulo à criatividade, à liberdade } \\
\text { de expressão; e } \\
\text { - Dificuldades em evitar avaliações } \\
\text { ou julgamentos prematuros e em } \\
\text { obter idéias originais. }\end{array}$ \\
\hline & 04 & $\begin{array}{l}\text { Trabalho em } \\
\text { grupo }\end{array}$ & $\begin{array}{l}\text { Com o levantamento referencial } \\
\text { realizado, os graduandos são } \\
\text { incentivados a organizar o trabalho } \\
\text { para ser apresentado em forma } \\
\text { escrita (texto) e oral (painéis). As } \\
\text { tarefas são divididas no grupo. }\end{array}$ & $\begin{array}{l}\text { - Permite que os graduandos se } \\
\text { responsabilizem por uma tarefa } \\
\text { e exercitem a capacidade de } \\
\text { organização; e } \\
\text { - É necessária a atenção para que o } \\
\text { trabalho não envolva apenas alguns } \\
\text { membros. }\end{array}$ \\
\hline & 05 & Debate & $\begin{array}{l}\text { Após a apresentação oral, os } \\
\text { graduandos são estimulados } \\
\text { a promover um debate, com } \\
\text { argumentos relacionados aos } \\
\text { diferentes assuntos abordados. }\end{array}$ & $\begin{array}{l}\text { - Desenvolvimento das habilidades } \\
\text { de falar em público e ordenar fatos e } \\
\text { idéias; e } \\
\text { - Desenvolvimento do aceite às } \\
\text { criticas e sugestões. }\end{array}$ \\
\hline \multirow{3}{*}{ 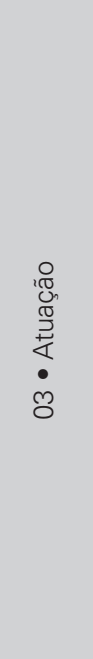 } & 06 & Imitação & $\begin{array}{l}\text { Os graduandos são orientados } \\
\text { a desenvolver uma proposta } \\
\text { projetual embasada nos conceitos } \\
\text { ambientais apresentados na etapa } \\
\text { 04, em um ambiente próximo. }\end{array}$ & $\begin{array}{l}\text { - Fixação dos conceitos teóricos } \\
\text { referenciais através do exercício; e } \\
\text { - Envolvimento profundo com o } \\
\text { tema da disciplina. }\end{array}$ \\
\hline & 07 & Projetos & $\begin{array}{l}\text { São realizadas as tarefas com } \\
\text { objetivos a serem alcançados em } \\
\text { um prazo maior: o desenvolvimento } \\
\text { do projeto. }\end{array}$ & $\begin{array}{l}\text { - Todo o grupo se responsabiliza } \\
\text { pelo desenvolvimento, inclusive, } \\
\text { diagnosticando suas possíveis falhas. }\end{array}$ \\
\hline & 08 & $\begin{array}{l}\text { Exploração do } \\
\text { ambiente local }\end{array}$ & $\begin{array}{l}\text { Com o projeto inserido na realidade } \\
\text { próxima, a compreensão do } \\
\text { conteúdo se torna mais fácil, ou } \\
\text { seja, ocorre uma interação dos } \\
\text { processos conceituais com o meio } \\
\text { ambiente. }\end{array}$ & $\begin{array}{l}\text { - Agradabilidade na execução; } \\
\text { - Grande participação dos } \\
\text { envolvidos; } \\
\text { - Vivência de situações concretas; e } \\
\text { - Despertar pela consciência } \\
\text { ambiental. }\end{array}$ \\
\hline
\end{tabular}

Quadro 2 • Estratégias propostas no desenvolvimento da disciplina

Cadernos de Arquitetura e Urbanismo, v.17, n.20, 2010 
3. Referencial bibliográfico, trabalho teórico e projeto produzido pelos grupos. sejam maiores a percepção e a participação dos envolvidos. Ao final do semestre todo o material produzido pelos graduandos ${ }^{3}$ é compartilhado em meio digital, o que contribui para a formação de um pequeno banco de dados, incentiva o aprofundamento do estudo individual e dissemina o conhecimento construído durante a disciplina. O Quadro 2 apresenta de forma sucinta as principais atividades, baseando-se em parâmetros estabelecidos pela Unesco/Unep/IEEP (EDUCAÇÃO..., 2000).

Ao percorrer todas as etapas, com as atividades já concluídas, é realizada uma exposição dos trabalhos no prédio do curso de arquitetura e urbanismo, para que os resultados sejam compartilhados com os demais graduandos da instituição. Com isso, o debate é ampliado e outros alunos se sentem atraídos pelo contexto. Os participantes, por sua vez, encaram o processo como um estímulo e são motivados a adotarem os conceitos e técnicas estudados como práticas corriqueiras em suas futuras experiências profissionais e pessoais.

\section{Relato de experiências da disciplina}

Os trabalhos produzidos pelos alunos abrangeram modelos diferentes de projeto. Nos dois primeiros semestres os graduandos tiveram como desafio apresentar um ensaio projetual alicerçado nos conceitos estudados na disciplina para a intervenção em um condomínio residencial horizontal, direcionado à classe média alta (Condomínio Residencial Pedra da Cebola). Localizado próximo à Universidade, possibilitou visitas constantes, facilitando os trabalhos. No período de desenvolvimento desses projetos, o condomínio estava em fase de construção. Nos lotes em que já haviam iniciado a construção das residências, os alunos não poderiam interferir e, nos demais lotes, caso fosse necessário e justificável, poderiam propor novas soluções que contribuíssem com melhorias relacionadas ao tema em estudo. Vários foram os recursos utilizados, tanto para o entorno das residências, as áreas comuns, quanto para o projeto da residência (cada grupo projetou uma unidade). O Quadro 3 resume algumas soluções, e os exemplos de projetos contribuem para a visualização de algumas dessas estratégias.

O segundo modelo adotou como projeto-base uma reforma. Os alunos desenvolveram por dois semestres consecutivos (2008/1 e 2008/2) o projeto de reforma do prédio do curso de arquitetura e urbanismo (Cemuni III), da Ufes. Foram apresentadas algumas restrições aos alunos: não poderiam alterar o formato do prédio, uma vez que este compõe, juntamente com outros quatro blocos, o Centro de Artes e todos possuem o mesmo partido arquitetônico. Além disso, todo o material a ser retirado deveria ser rigorosamente justificado e apresentada uma proposta para reúso ou destinação correta para os resíduos provenientes de uma possível demolição. O prédio possui espaços mal dimensionados, não há ventilação e iluminação natural suficientes nas salas, há pouca valorização do pátio interno, a acessibilidade é restrita etc. As intervenções correlatas à temática em estudo e que foram apresentadas tanto para a edificação como para o entorno imediato e o estacionamento estão brevemente descritas no Quadro 4. Com os resultados desses trabalhos, verificou-se 
Quadro 3 • Resumo de soluções de projeto adotadas para o condomínio residencial que é possível aplicar estratégias sustentáveis em projetos já consolidados, reduzindo-se o impacto ambiental e aumentandose a qualidade de vida dos usuários.

\begin{tabular}{|c|c|}
\hline \multirow{9}{*}{ Entorno da moradia } & Inserção de vegetação e áreas verdes para melhor conforto ambiental \\
\hline & Estudos de mobilidade envolvendo também a escala do pedestre \\
\hline & $\begin{array}{l}\text { Uso das tipologias da infraestrutura verde, como jardins de chuva, biovaletas etc. } \\
\text { (Figura 2), além de conceitos da permacultura e slow streets }\end{array}$ \\
\hline & Paisagismo produtivo \\
\hline & Estacionamento coletivo \\
\hline & Sombreamento dos percursos nas áreas comuns (Figuras 3 e 4) \\
\hline & Pavimentação permeável ou semipermeável \\
\hline & $\begin{array}{l}\text { Lixeiras adequadas para segregação dos resíduos secos com o intuito de facilitar } \\
\text { a coleta seletiva e contribuir para a educação ambiental }\end{array}$ \\
\hline & Compostagem dos resíduos orgânicos do condomínio \\
\hline \multirow{6}{*}{$\begin{array}{l}\text { Projeto da } \\
\text { residência }\end{array}$} & Estudos de conforto (iluminação e ventilação natural etc. - Figura 5) \\
\hline & Aproveitamento de energia solar para aquecimento de água \\
\hline & Tetos verdes \\
\hline & $\begin{array}{l}\text { Escolha de materiais de menor impacto ambiental (materiais certificados, reciclados, } \\
\text { reaproveitados, que incorporem outros materiais descartados como subprodutos etc.) }\end{array}$ \\
\hline & Aparelhos e sistemas hidráulicos e elétricos economizadores \\
\hline & Tratamento e reúso de águas servidas e de água da chuva (Figura 5) \\
\hline
\end{tabular}

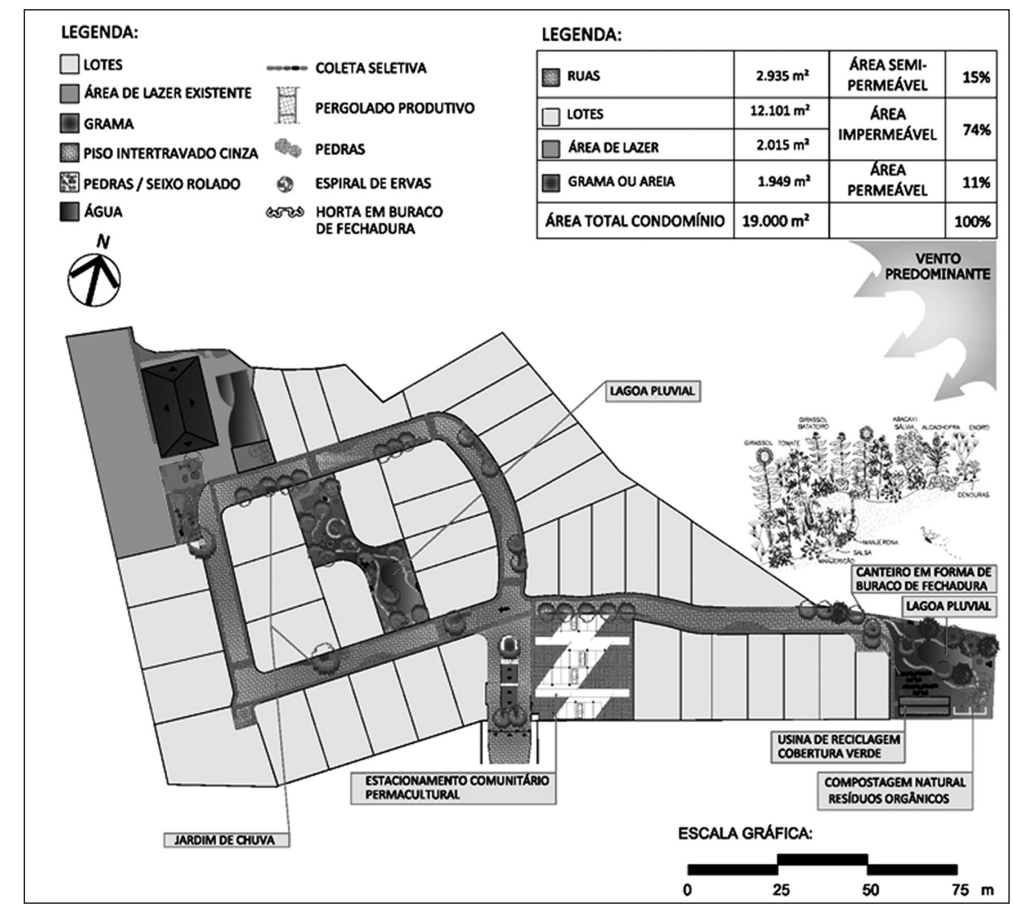

Figura 2 • Implantação do condomínio com inserção de tipologias da infraestrutura verde. Alunas: Márcia Bandeira e Karolyna Costa Aguiar - 2007/2. 
Figura 3 - Sombreamento dos percursos nas áreas comuns com vegetação e pergolados.

Alunas: Márcia Bandeira e Karolyna Aguiar - 2007/2.

Figura 4 • Detalhe do pergolado. Alunas: Márcia Bandeira e Karolyna Aguiar - 2007/2
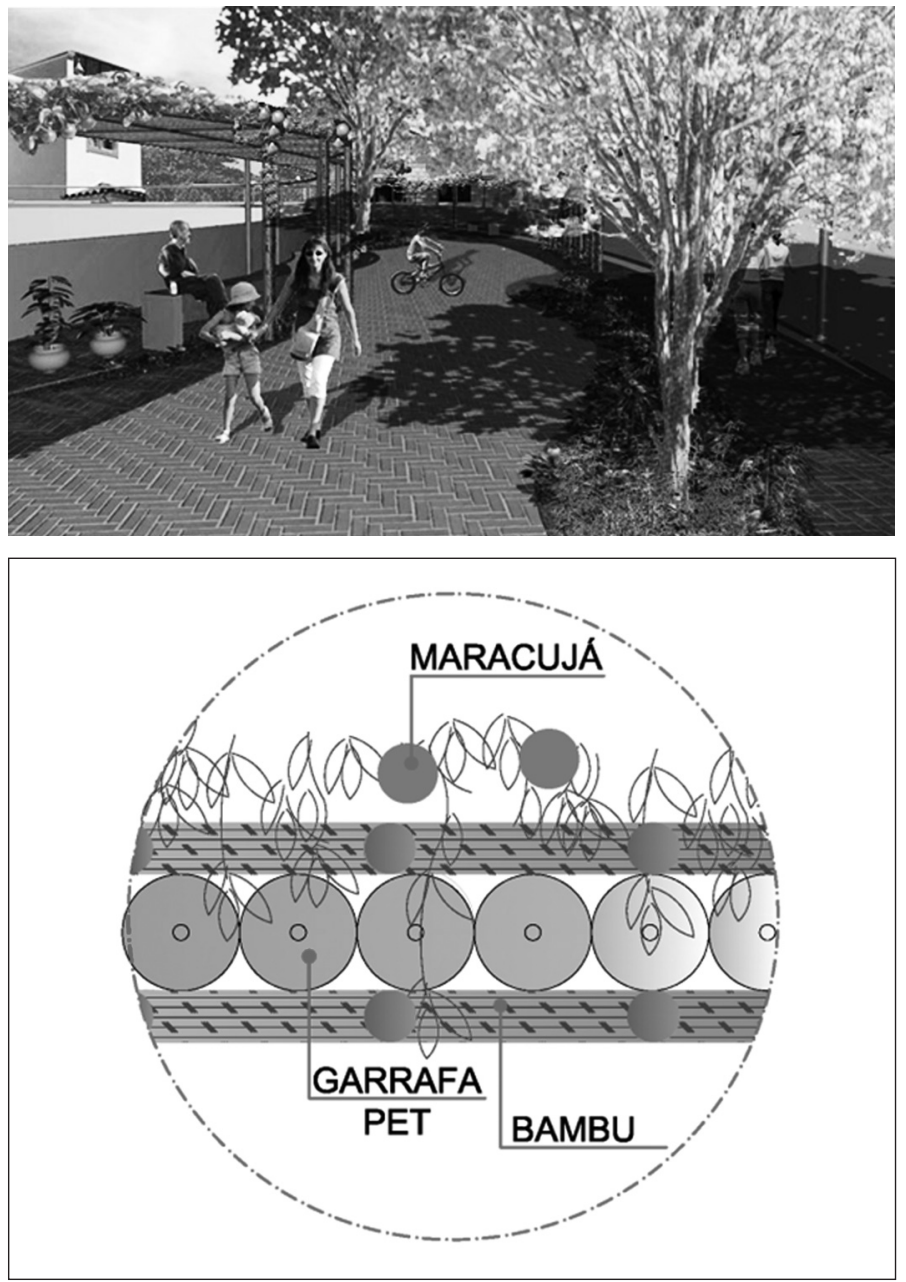

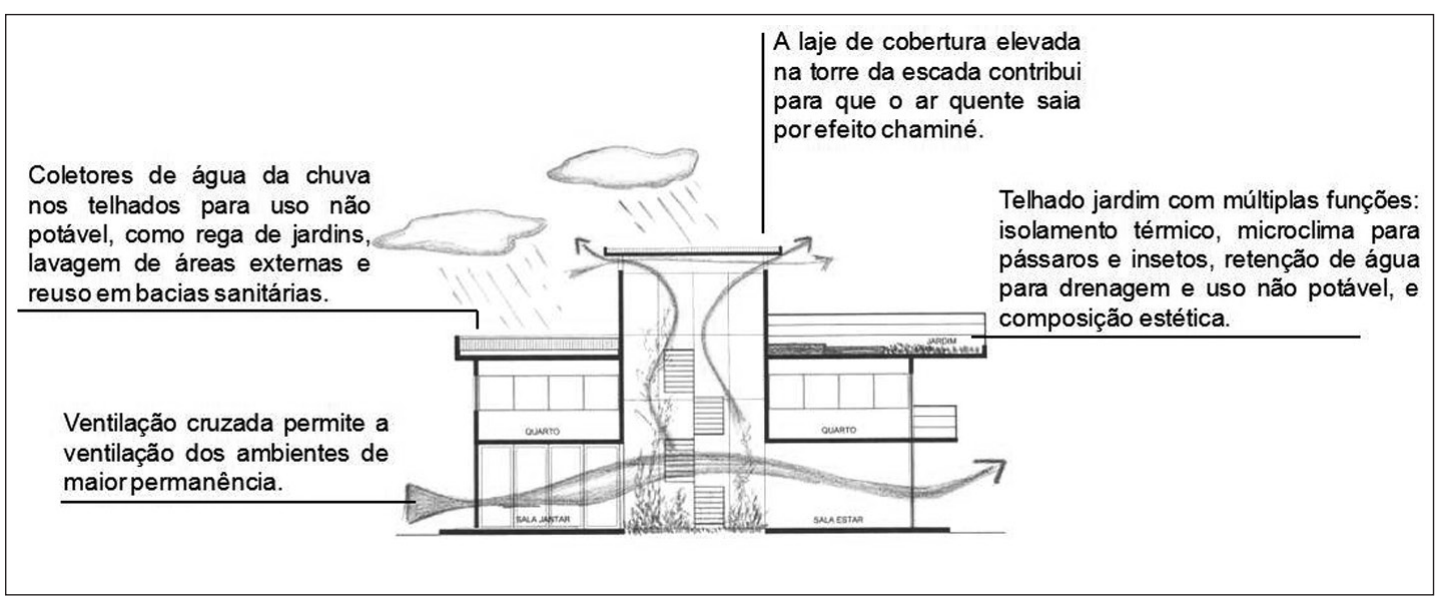

Figura 5 • Estudo de conforto e captação de água da chuva. Alunos: Bruna Plácides e Fernando dos Santos - 2007/2. 
Entorno imediato e estacionamento

Reforma do Cemuni III

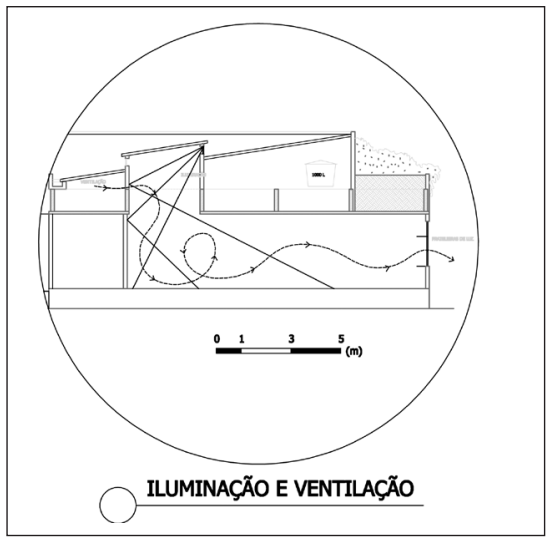

Figura 6 • Ventilação natural otimizada pela elevação do telhado e iluminação interna beneficiada com a inserção das prateleiras de luz.

Alunos: Sabrina Moura, Natália Lira, Marcos Lamego, Valdinéia Selim 2008/1

Figura 8 - Estudo de mobilidade e localização dos pontos para coleta seletiva.

Alunos: Jaqueline Pugnal, Juliana Tusholska, Patrícia Borgo e Pollyana Meneghelli - 2008/1.

Cadernos de Arquitetura e Urbanismo, v.17, n.20, 2010

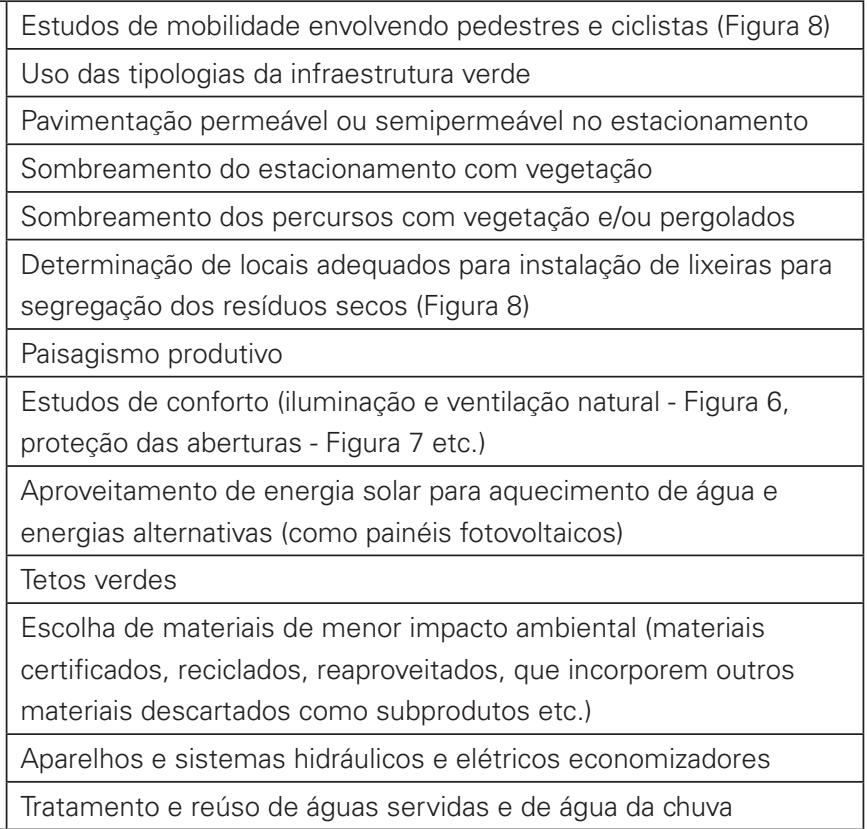

Figura 7 • Inserção de pergolado e vegetação para proteção das aberturas. Alunos: Adriana Hiromi, Agnes Thompson, Martha Moça e Paulo Valentin 2008/1.
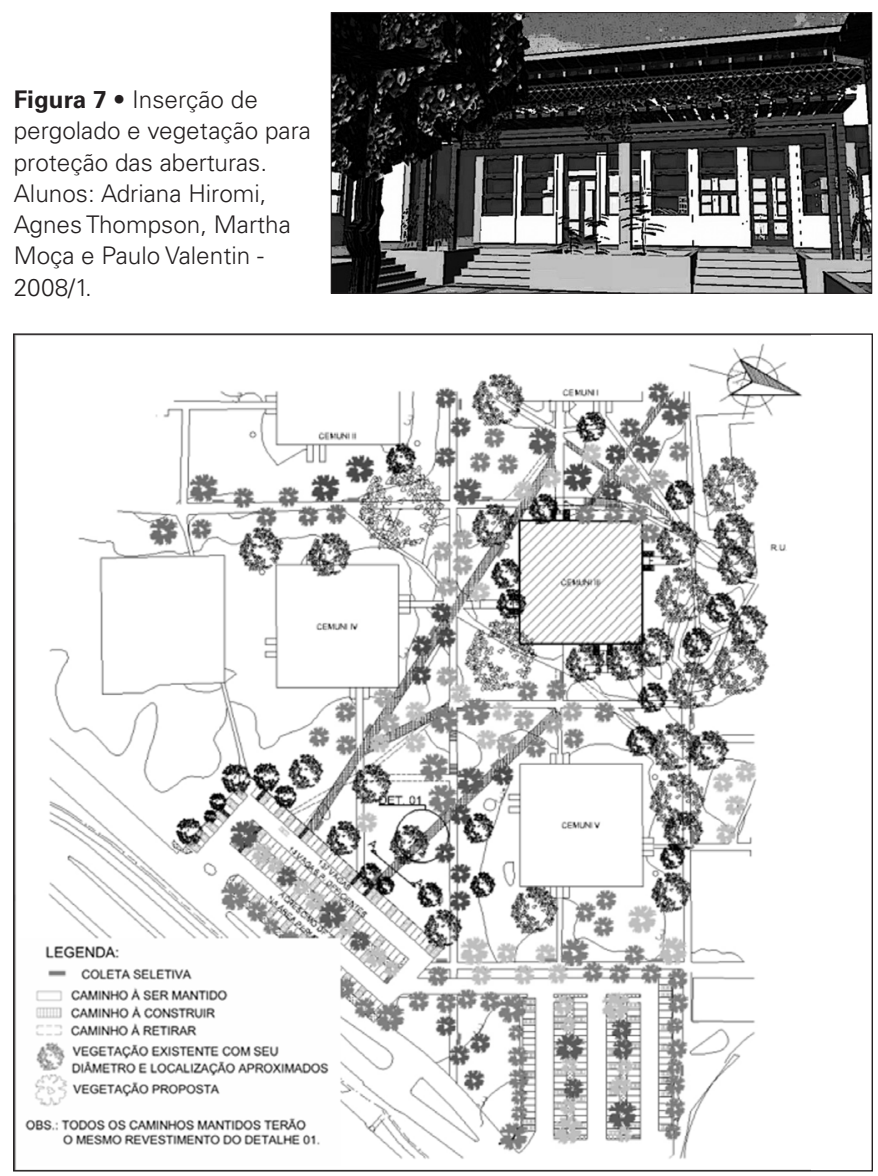


\section{Percepções quanto à metodologia proposta}

Como resultado preliminar, é possível listar algumas percepções conclusivas do processo metodológico, tais como:

- Melhor interação entre os participantes de cada grupo constituído e também entre os grupos distintos;

- Conhecimento de novos enfoques e assuntos;

- Rompimento de paradigmas relacionados ao tema;

- Rompimento de paradigmas relacionados ao método de trabalho em grupo, em que puderam ficar evidentes as singularidades de ideias e sentimentos de cada membro envolvido no processo;

- Fixação dos conceitos teóricos referenciais através do exercício - atividade prática;

- Efetiva interação do tema da educação ambiental com a disciplina Projetos Especiais;

- Organização das atividades e consequente ordenamento de todos os exercícios desenvolvidos:

- Vivência de situações concretas;

- Despertar da consciência ambiental;

- Constatação de que é necessário o envolvimento de docentes de outras disciplinas e também de outros cursos, pois esta é ainda uma iniciativa pontual e que requer o amadurecimento e o envolvimento de outros profissionais;

- Constatação de que é necessária a definição de políticas pedagógicas de direcionamento das ações em prol de um amadurecimento de metodologias vinculadas à educação ambiental; e

- Boa aceitabilidade da metodologia, repercutindo em bons trabalhos.

Também é possível listar alguns resultados correlatos ao conteúdo apresentado e ao envolvimento dos graduandos:

- Grande concorrência para as vagas disponíveis;

- Realização de projetos de alta qualidade;

- Desenvolvimento da autoconfiança e da participação, com ênfase no envolvimento de todos;

- Desenvolvimento das habilidades de falar em público e ordenar a apresentação de fatos e ideias;

- Desenvolvimento do aceite às críticas e sugestões propostas pelo docente ou por outros graduandos; e

- Contribuição para a concretização de sociedades mais sustentáveis, estabelecendo valores, ampliando as relações sociais, os conhecimentos, as competências e, em especial, desenvolvendo a formação da comunidade universitária como profissionais conscientes.

\section{Conclusões}

Acredita-se que a prática da educação ambiental é uma importante ferramenta capaz de proporcionar mudanças efetivas no contexto das cidades e na geração de uma sociedade cada vez mais consciente. Além disso, contribui para a concepção de uma nova mentalidade entre os futuros profissionais, inseridos e envolvidos com o conceito ambiental comprometido com a transformação social. 
A inserção da temática da educação ambiental e sustentabilidade em disciplinas de diversos cursos de universidades tem grande relevância para a formação de profissionais adaptados a uma filosofia ambiental. O objeto aqui apresentado muito tem a contribuir para uma nova forma de ensino, sustentada pelos aspectos ambientais e, consequentemente, de projetar os espaços, tendo como paradigma um instrumento capaz de cooperar com a superação de cada desafio imposto pelas decisões projetuais.

Os resultados obtidos sustentam a ideia de que se faz necessário planejar e seguir critérios no sentido de projetar, construir e ter uma vida saudável e com embasamento sustentável. O papel do arquiteto se destaca pelo fato de ser o responsável pelo projeto de edificações que deixam marcas na sociedade e no meio ambiente por muitos anos. Assim, o arquiteto deve encaminhar suas decisões de projeto em prol da preservação dos bens naturais, seja através de uma especificação correta de materiais, seja através de uma decisão capaz de conduzir a mudanças culturais e à incorporação de hábitos ambientais saudáveis por parte do ser humano.

Uma postura diferencial no ensino superior é fator essencial na concepção de uma nova geração de profissionais. A inclusão dos conceitos de sustentabilidade e educação ambiental nas instituições acadêmicas, não só na formação do arquiteto e urbanista como em tantos outros cursos, tem uma relevância fundamental.

A incorporação de temas relacionados a diferentes disciplinas contribui para uma atuação profissional em que estejam naturalmente inseridas nos hábitos projetuais as características de atitudes direcionadas à sustentabilidade. Os resultados obtidos junto à disciplina Projetos Especiais ainda são uma iniciativa inicial e isolada. O processo requer o amadurecimento e o envolvimento de docentes e discentes de outras disciplinas e cursos da UFES e também de outras instituições de ensino superior.

Além disso, é necessária a definição de políticas pedagógicas de direcionamento das ações, para que se possa envolver o maior número possível de docentes. Embora não se tenha discutido o interesse de alunos pelo tema aqui apresentado, destaca-se o fato de que, nas monografias obrigatórias de conclusão de curso, torna-se cada vez mais evidente o aumento da escolha por temas relacionados à sustentabilidade e à educação ambiental. Isso vem acontecendo nos últimos semestres no curso de Arquitetura e Urbanismo. Também é crescente o número de alunos admitidos nos cursos de pós-graduação, interessados em desenvolver pesquisas sobre o assunto, em geral abrangido pela metodologia e conteúdos apresentados nessa disciplina.

Acredita-se que explorar questões relacionadas a decisões projetuais embasadas em conceitos sustentáveis e na qualidade do ambiente construído é uma importante ferramenta mitigadora dos desafios impostos pelos paradigmas atuais. Além disso, tal iniciativa mostra-se capaz de proporcionar mudanças efetivas no contexto urbano e na geração de uma nova cultura. Nesse sentido, é perceptível que o ser humano precisa adotar uma nova postura em relação à natureza, para que possa promover o ajuste entre práticas econômicas e desenvolvimentistas, com reflexos positivos sobre a qualidade de vida de todos. 


\section{Agradecimentos}

Agradecimento especial aos ex-alunos da disciplina Projetos Especiais, que sempre estiveram prontos a descobrir novos caminhos, em especial aos que forneceram os projetos para ilustrar o artigo.

\section{Referências}

ANDRADE, L. M. S. de S.; ROMERO, M. A. B. Desenho de assentamentos urbanos sustentáveis: proposta metodológica. In: CONFERÊNCIA LATINO-AMERICANA DE CONSTRUÇÃO SUSTENTÁVEL, 1.; ENCONTRO NACIONAL DE TECNOLOGIA DO AMBIENTE CONSTRUÍDO, 10, 2004, São Paulo. Anais... São Paulo, 2004, p. 18-21.

BRASIL. Lei n 9.795, de 27 de abril de 1999. Dispõe sobre a educação ambiental, institui a Política Nacional de Educação Ambiental e dá outras providências. Brasília, 1999. Disponível em: <http://www.planalto.gov.br/CCIVIL/LEIS/L9795.htm>. Acesso em: 24 abr. 2009.

BRÜGER, Paula. Educação ou adestramento ambiental? Florianópolis: Letras Contemporâneas, 1999.

DUARTE; D.; MULFARTH, R. K.; GONÇALVES, J. Sustentabilidade ambiental urbana no ensino de graduação; proposta do departamento de tecnologia da FAUUSP. In: ENCONTRO NACIONAL DE CONFORTO NO AMBIENTE CONSTRUÍDO, 9.; ENCONTRO LATINO- AMERICANO DE CONFORTO NO AMBIENTE CONSTRUÍDO, 5, 2007, Ouro Preto. Anais... Ouro Preto, 2007, p. 610619.

EDUCAÇÃO ambiental. 2000. Disponível em: <http://www.ambientebrasil.com.br/composer.php3?base=./educacao/index. php3\&conteudo=./educacao/educacao.html>. Acesso em: 24 abr. 2009.

SANTOS, R. E. dos. Currículo e qualidade de ensino. Cadernos de Arquitetura e Urbanismo, Belo Horizonte, v. 10, n. 11, p. 107-123, dez. 2003.

TRISTÃO, M. Políticas públicas da educação ambiental na formação de professores (as). In: ENCONTRO ESTADUAL DE EDUCAÇÃO AMBIENTAL, 3.; ENCONTRO DA REDE CAPIXABA DE EDUCAÇÃO AMBIENTAL, 1, 2004, Vitória. Anais... Vitória, 2004, p. 36-51.

\section{Endereço para correspondência}

Márcia Bissoli

Rua Prof. Zilda Andrade, 165/ 303, Ed. Alamanda, Bairro de Lourdes - 29042-751-Vitória - ES

marciabissoli@gmail.com 